\title{
ZAGZEBSKI ON AUTHORITY AND PRE-EMPTION IN THE DOMAIN OF BELIEF
}

\section{ARNON KEREN}

University of Haifa

Linda Zagzebski's Epistemic Authority: A Theory of Trust, Authority, and Autonomy of Belief is an important contribution to the study of epistemology, and social epistemology in particular. It is also a very timely contribution. For too long, epistemologists and social epistemologists have talked about authority in the domain of belief without paying enough attention to the very concept of epistemic authority. Zagzebski's book is bound to change this.

Zagzebski presents a detailed account of the concept of epistemic authority, describing the essential features of authority which allow us to talk of authority both in the practical realm and in the realm of belief. Building on Joseph Raz's account of political and practical authority, she claims that to have authority is to have a special kind of normative power: 'a normative power that generates reasons for others to do or to believe something preemptively.' (Zagzebski 2012: 102) Thus she has directed the philosophical community's attention to an important concept that has previously received only little attention: to the concept of pre-emptive reasons for belief, a reason for belief that 'replaces other reasons the subject has' (Zagzebski 2012: 102), rather than being added to them. ${ }^{1}$ She has thus done more than anyone else to bring to the attention of the philosophical community the two central concepts,

\footnotetext{
${ }^{1}$ Raz himself has in passim addressed the applicability of his account of practical authority to the domain of belief. See, e.g., Raz (1986: 29-30, 52-3); (2006: 1032-7). In Keren $(2006 ; 2007)$ and elsewhere, I have studied the concept of epistemic authority, and the applicability of the Razian account to it. Like Zagzebski, I have defended the applicability of the notion of pre-emptive reason to the domain of belief and its centrality to our understanding of epistemic authority. Nonetheless, Zagzebski's recent account differs from my own, and my discussion here will touch upon some of the differences.
} 
of epistemic authority and of pre-emptive reasons for belief, and the relation between them.

With some qualifications, I think that Zagzebski's central claims about the conceptual relations between these two concepts are correct. I also agree with her central normative claim that we are often justified in believing on authority, and are sometimes rationally required to do so. Indeed, I have defended similar conceptual and normative claims in my Ph.D. dissertation (Keren 2006) and in subsequent writings (Keren 2007; 2014). Nonetheless, I think that in arguing for these claims, Zagzebski has ignored important differences between practical authority and authority in the domain of belief, and that as a result her attempt to explain why it is rational to believe on authority is lacking. Because I think that these differences are of much epistemological significance, my discussion here will focus on Zagzebski's attempt to show that Raz's account of political authority, when properly interpreted, is applicable to the domain of beliefs (Zagzebski 2012: ch. 5), and will try to show where her application of the Razian account goes wrong. Obviously, this will leave untouched much of what Zagzebski does in this rich and important book.

Raz develops his account of authority by claiming that a number of theses - content independence, the pre-emption-, dependence-, and normal justification theses - are true of political authorities, and that some - e.g., the no-difference thesis - are not. Zagzebski attempts to show that analogues of the theses that are satisfied by political authorities are also satisfied by epistemic authorities; and that the no-difference thesis, which is not true of political authorities, is also not true of epistemic authorities. Thus, the basic contours of epistemic authority match the contours that Raz ascribes to political authority.

This, I argue, is only partly true. Starting with the conceptual claim about what epistemic authority and believing on authority consist in, I argue ( $\$ 1)$ that Zagzebski is correct in identifying the pre-emptive nature of reasons provided by an authority as central to our understanding of epistemic authority. Thus Zagzebski is correct that Raz's pre-emption thesis is satisfied by epistemic authority. However, while this central feature is shared by epistemic and political authorities, other significant features are not. Thus, I argue ( $\$ 2)$ that the no-difference thesis, when interpreted in the way intended by Raz, is true of epistemic authorities, despite being false of political authorities, and that Zagzebski's characterization of the distinguishing feature of authority can therefore 
be misleading. Finally, I turn to the rationality of believing on authority (§3): I argue that Zagzebski’s attempt to show that an analogue of the normal justification thesis applies to the domain of belief again ignores key differences between belief and action, and that her explanation of the rationality of believing on authority therefore fails. A successful explanation of this will need to be more attuned to the differences between political and epistemic authorities.

\section{AUTHORITY, TRUST, AND PRE-EMPTION}

Zagzebski opens her book by noting that authority in the domain of belief, unlike practical authority, receives little attention in contemporary philosophy. Her aim is to change this, and to convince us of the rationality of believing on authority. Focusing mainly on the point of view of the subject, of a subject asking herself 'how she should get beliefs she accepts upon reflection', she claims that 'we are all committed to accepting epistemic authority' (Zagzebski 2012: 2-3). Her argument for this claim is built of two main stages. In the first, she argues that epistemic-trust in others is not rationally escapable. By virtue of our rational, inescapable trust in ourselves, and by virtue of the similarity between ourselves and others, we are committed to placing epistemic-trust in others. ${ }^{2}$ At the second stage she attempts to establish that 'among those we are committed to trusting are some whom we ought to treat as epistemic authorities' (Zagzebski 2012: 3).

As noted, the second stage of Zagzebski's argument builds heavily - at times too heavily, I shall argue - on Joseph Raz's account of political authority. Zagzebski adopts two main Razian themes: one conceptual, one normative. The first involves claims about the conceptual relations between epistemic authority and the normative power to generate pre-emptive reasons for belief, and the centrality of the latter for our understating of what believing or acting on authority consists in. The normative claim is that it is rational for us to believe on authority, and that what justifies belief on authority parallels what, according to Raz, justifies acting on someone's authority.

Let us start by considering the conceptual question. Zagzebski does not seem to present an argument for the claim that believing on authority

${ }^{2}$ A second feature of self trust that commits us to epistemically trusting others is our rational trust in our emotions, and in particular, in our epistemic admiration of others (Zagzebski 2012: 93). 
essentially involves taking the authority's belief as issuing a pre-emptive reason for belief. Nonetheless, there are reasons to think that she is correct about this. One type of consideration supporting this claim is based on the kind normative responses that are open to us when we invite others to treat us as epistemic authorities, or when we advise others to form beliefs on a person's authority. If to have epistemic authority is to have the normative power to generate pre-emptive reasons for belief, then there should be distinct forms of criticism that will be open to us when we think that a thinker should treat another as an epistemic authority: her refusal to let the authority's belief replace her own consideration of the evidence will then count as grounds for criticizing her. Indeed, this is a form of criticism we are apt to make when we think that a subject should believe upon others' authority, e.g., when we think that laypersons should defer to the authority of scientists but they refuse to do so, ${ }^{3}$ or when children refuse to defer to the epistemic authority of their parents. Correlatively, forms of criticism that are often available to us should not be available to us when we think that a subject should treat another as an epistemic authority: if we point out to person $A$ that she should believe that $p$ on $B$ 's epistemic authority, then we cannot at the same time suggest that $A$ should weigh all the relevant evidence available to her, or criticize her for not doing so. Indeed, such criticism of a subject does seem to be incompatible with the suggestion that he should believe on another thinker's authority.

Such considerations lend support to Zagzebski's claim about the conceptual relations between having epistemic authority, and having the power to generate pre-emptive reasons for belief. However, they may also suggest that her characterization of the distinguishing feature of epistemic authority in these terms should be slightly amended. For there are reasons to think that being epistemically trustworthy also involves the power to issue pre-emptive reasons for belief, and that one can be thus trustworthy on an issue without having epistemic authority on it.

Thus, consider a speaker, Trevor, who address us and says: 'Trust me, $p$ '. And suppose that we do form the belief that $p$, and do so without considering evidence available to us which is relevant to the truth of $p$. Trevor, it seems, cannot then criticize us for not considering all the evidence available to us. Such criticism seems to be incompatible with his invitation to us that we trust him. If he were to criticize us in this

\footnotetext{
${ }^{3}$ See e.g. Jones (2002).
} 
way, he would seem to be withdrawing his original appeal to us that we trust him (Keren 2014). Compare this with the case of Esther, who intentionally provides us with very good evidence for $p$, expecting us to recognize this intention of hers. If here we also form the belief that $p$ without weighing other available evidence, Esther, it seems, can criticize us by saying: 'You are correct. But you should have considered all the evidence before reaching that conclusion.' Such criticism, whether valid or not, seems to be perfectly compatible with her expectation of us that we recognize that she intends to provide us with very good evidence, but not with Trevor's expectation that we trust him.

Thus, there are forms of criticism that are often available to us, but that are not compatible with inviting someone to trust, or with advising someone to form a belief upon epistemic trust. And these are the very forms of criticism that we should expect to be closed, if pre-emption is central not only to believing on authority, but also to believing on trust. The point is not merely that sometimes a trustworthy person's belief can provide us with pre-emptive reasons. The point is a conceptual point about trust and trustworthiness. Trusting a person, quite generally, requires seeing yourself as having, in virtue of the person's trustworthiness, reason against taking certain precautions, and thus as having pre-emptive reasons for action or belief (Keren 2014): ${ }^{4}$ You do not trust the babysitter, if you don't think that in virtue of her trustworthiness, you have reason not to install, as a precaution, nanny cameras throughout the house; you do not trust a thinker for the truth, if you don't think that in virtue of her trustworthiness, you have reason not to weigh all evidence available to you, just as a precaution.

This might require introducing a minor revision in Zagzebski's account of the distinguishing features of epistemic authority. For we might want to distinguish, as Zagzebski does, between being epistemically trustworthy and having epistemic authority, and between believing on trust, and believing on authority. ${ }^{5}$ Even if our notion of trust essentially involves the idea of pre-emption, there is a distinction to be

${ }^{4}$ Reasons against taking precautions are reasons against acting for precautionary reasons. Hence they are reasons against acting for certain other reasons, and hence, preemptive reasons. See Keren (2014).

${ }^{5}$ Zagzebski assumes that we can believe upon trust without believing on authority because she employs a notion of epistemic trust weaker than the one singled-out here, and which entails seeing a trusted thinker's belief that $p$ as providing us with a primafacie reason for believing $p$, but not with a pre-emptive reason for believing $p$. 
made between the kind of pre-emptive reasons for belief provided by the report of an authoritative expert, and the pre-emptive reasons for belief typically provided to the expert by a trustworthy layperson's report. Even if the expert trusts the layperson, she may not treat her as an authority. But then it is not the ability to generate pre-emptive reasons for belief that distinguishes having epistemic authority from being epistemically trustworthy. What distinguishes between the two is the force of the preemptive reasons that one has the power to generate. The belief of epistemic authorities provides me with pre-emptive reasons for belief that make it epistemically irresponsible for me to form the relevant belief on my own weighing of the evidence. In contrast, the beliefs of trustworthy thinkers give me reasons that need not render it epistemically irresponsible for me to form the belief on my own weighing of the evidence, even if they also make it responsible for me to allow the expert's belief to pre-empt my own. In this sense, what is distinctive of epistemic authority is that it is the normative power not just to provide others with reasons to believe something pre-emptively, but that it is the power to generate to others an epistemic duty to believe something pre-emptively. ${ }^{6}$

\section{GENERATING PRE-EMPTIVE REASONS FOR BELIEF}

Believing on authority thus involves seeing ourselves as having a preemptive reason for belief. There is thus a sense in which Zagzebski is correct that one has epistemic authority only if one has the normative power to generate such reasons. However, there is an important sense of 'generating reasons' in which this is false: a sense in which practical authorities indeed have the normative power to generate reasons to do things pre-emptively, but in which epistemic authorities do not have the normative power to generate pre-emptive reasons for belief. This is arguably an important aspect of a proper understanding of the working of pre-emptive reasons for belief and of the very concept of epistemic authority.

In presenting his account of practical authority, Raz discusses, and rejects, what he calls the no-difference thesis, according to which, 'the

${ }^{6}$ In this sense, the kind of normative power distinctive of epistemic authorities is more similar to the normative power of practical and political authorities than Zagzebski's formulation suggests. To say that I have (practical) authority over my son is to say not only that I can generate reasons for him to do things pre-emptively, but that I can generate duties for my son (Enoch 2014). 
exercise of authority should make no difference to what its subject ought to do for it ought to direct them to do what they ought to do in any event' (Raz 1986: 48). Raz rightly rejects this thesis when applied to practical authorities: an authoritative directive stating that we must all drive on the left-hand side of the street can create for us a duty to drive on the lefthand side of the street, where we wouldn't have such a duty otherwise.

Zagzebski claims that the epistemic analogue of the no-difference thesis is also false. If the analogue is that 'the fact that an epistemic authority believes a certain proposition $p$ should make no difference to what I ought to believe', as Zagzebski suggests (2012: 109), then she is probably correct about that. Epistemic authorities do generate reasons in the weak sense that knowing what they believe often makes a difference to what we ought to believe. But such a reading of the no-difference thesis is not the one intended by Raz. In discussing the thesis, Raz clearly has in mind a stronger sense of 'generating reasons'. For the no-difference thesis which Raz rejects does not deny that authoritative pronouncements have epistemic significance; instead, it denies that authoritative pronouncements have normative significance beyond their epistemic significance. According to the thesis, ' $[t]$ here is nothing which those subject to authority ought to do as a result of the exercise of authority which they did not have to do independently of the exercise, they merely have new reasons for believing that certain acts were prohibited or obligatory all along' (Raz 1986: 30; emphasis mine). This is arguably false of practical authorities, for an authoritative command can create for us a good reasons to $\Phi$ (to drive on the left-hand of the street), in the sense that had the command not been given, no one would have had a reason, let alone a duty, to $\Phi$; nonetheless, the reasons to $\Phi$ generated by the command is a perfectly good reason. In contrast, an authoritative speaker's testimony or belief that $p$ cannot generate for us reasons to believe that $p$ in this strong sense. If the authoritative thinker did not have good reasons to believe that $p$ herself, then the reason to believe that $p$ generated by her testimony that $p$ is not a good reason. It is a misleading reason.

Therefore, to have epistemic authority, is to have the normative power to generate for others reasons to believe something pre-emptively, but not in the sense in which to have practical authority is to have the power to generate for others reasons to do something pre-emptively. Practical authorities can, but epistemic authorities cannot, generate reasons in the strong sense which figures in Raz's discussion. An epistemic authority 
cannot provide us with good reasons for belief if she does not have one herself; she can merely give us good reasons to believe $p$ if there were good reasons to believe $p$ all along. It might therefore be more accurate to say that epistemic authority consists in the power to pre-emptively transfer to others good reasons for belief. Or better: to provide others with pre-emptive reasons for belief that allow the authority's good reasons for believing something to support others' belief in the same thing.

Importantly, this strong sense of 'generating reasons', which figures in Raz's discussion, and which distinguishes between epistemic and practical authority, is one that should interest epistemologists interested, like Zagzebski, in figuring out how consideration of authority figures in the reflective subject's own perspective. When we believe that $p$ on a speaker's authority, this is only because we believe that she herself has, independently of her telling us that $p$, a good reason to believe that $p$. More broadly, it is this strong sense of 'generating reasons' that should interest epistemologists in their attempt to understand how, and under what conditions, we can obtain knowledge by trusting other thinkers. Thus an appreciation of the sense in which epistemic authority cannot generate reasons to believe allows us to make better sense of the controversy over the principle stating that testimony does not generate knowledge: the principle stating that a hearer can come to know that $p$ on the basis of a speaker's testimony that $p$ only if the speaker herself knows that $p$. In recent years, a number of apparent counter-examples have emerged to this principle: cases in which a hearer appears to come to know that $p$ on the basis of the testimony of a speaker who does not know that $p$ (Graham 2000). Armed with an understanding of the sense in which epistemic authorities cannot generate reasons preemptively, we can understand in what sense this principle is correct, in spite of apparent counter-examples; we can understand why it is right to dismiss these counterexamples as cases where knowledge is based on testimony but not in the normal way (Williamson 2000: 257). To trust a speaker, we have noted, is to see her testimony as providing us with pre-emptive reasons to believe what she says; but epistemic authorities, and epistemically trustworthy speakers more generally, can generate pre-emptive reasons for belief only in the weak sense. Thus the reason made available to audiences by the speaker's testimony, in as much as it is made available to them through the distinctive normative structure associated with trust, cannot be stronger than the reason available to the speaker herself. In as much as a belief owes its epistemic status to 
trust, its epistemic status cannot be better than the epistemic status of the belief of the trusted person. If a hearer comes to know by believing an unknowing speaker's testimony, this can only be because her testimonially-based belief is supported by other reasons beyond the reasons for belief provided by the testimony itself, reasons which were not pre-empted by the speaker's testimony. Therefore, the justification for the hearer's belief is not a product of the distinctive normative structure associated with epistemic trust and authority, and her way of gaining knowledge is not the normal way of obtaining knowledge through testimony (Keren 2007).

\section{JUSTIFIED BELIEF ON AUTHORITY}

The characterization of the distinguishing features of epistemic authority leaves open the question whether we should ever form a belief on a person's authority: Should we ever treat the fact that a putative authority believes that $p$ not just as a reason for believing $p$, but as one that has preemptive force? Zagzebski defends a positive answer to the question, and does so by applying to the domain of belief another Razian thesis - the normal justification thesis (NJT).

According to NJT,

the normal way to establish that a person has authority over another person involves showing that the alleged subject is likely better to comply with reasons which apply to him (other than the alleged authoritative directives) if he accepts the directives of the alleged authority as authoritatively binding and tries to follow them, rather than by trying to follow the reasons which apply to him directly. (Raz 1986: 53)

Zagzebski adopts an analogous thesis about the justification of epistemic authority:

Justification Thesis 1 for the Authority of Belief (JAB 1): The authority of another person's belief for me is justified by my conscientious judgment that I am more likely to form a true belief and avoid a false belief if I believe what the authority believes than if I try to figure out what to believe myself. (Zagzebski 2012: 110)

She then employs a Razian argument - the financial shares argument (Raz 1986: 67-69) - to show that the conditions set by JAB1 are indeed satisfied by pre-emptively believing on authority. 
There are thus two questions to ask about Zagzebski's NJT-based argument for the justification of believing on authority: (1) does JAB1 indeed set a correct standard for the justification of belief on authority? (2) Does Raz's financial shares argument, when applied to the case of belief, indeed show that believing on authority satisfies the conditions set by JAB1? It seems to me that Zagzebski's positive answer to both questions is mistaken. Zagzebski seems to ignore important differences between the practical and the epistemic domain, which undermine her application of the Razian justification of acting on authority to the justification of believing on authority.

Consider first the standard of justification set by JAB1. Both NJT and JAB1 assume a strong connection between doing the best one can, and being justified. NJT assumes that acting on authority is justified if and because doing so is the best way one has of complying with reasons that apply independently. Similarly, JAB1 assumes that believing on authority is justified if and because doing so is the best way one has of achieving the epistemic goals of believing truth and avoiding error. However, there are reasons for doubting the parallel between NJT and JAB1; even if NJT sets standards sufficient for justification in the practical domain, the same is not true of the standards set by JAB1 for the domain of belief. In the practical domain, there is a tight connection between what one can best do, and what one is justified in doing. Thus, very different moral theories can all agree that an agent ought to perform an act if and only if it is the best action that she has available (while disagreeing on what makes an action 'best'). ${ }^{7}$ However, this kind of intimate relation does not exist in the case of belief: that one can do no better than form a belief in a certain way does not mean that the belief is epistemically justified. If the only belief-forming mechanisms available to a thinker are unreliable and yield beliefs that do not fit the evidence, then the fact that a belief was formed by using the least unreliable belief-forming mechanism available does not mean that the belief is epistemically justified.

\footnotetext{
${ }^{7}$ See, e.g., Zimmerman (1996). Some views about supererogation might attempt to loosen this strong connection between 'ought' and 'good', to allow for the possibility of actions that are beyond the call of duty: thus they would allow that action $A$ may be better than $B$, but that we have no duty to perform $A$ and may permissibly perform $B$. But even such views preserve the following strong relation between 'best' and 'ought'. Even if one may perform an action which is not best, in the relevant sense of 'best' picked by the moral theory, it is always the case that one may also perform whatever action is best. No moral theory would suggest that an action which is best cannot justifiably be performed.
} 
Accordingly, the known inferiority of other belief-forming strategies available to me does not suffice to show that I am justified in believing on the authority of another person. Suppose that ignorant $\mathrm{Al}$ knows that if he himself tries to figure out what to believe on a certain question, he is very likely to form a false belief, and that the likelihood of mistake will be slightly lower, but still very high, if he treats sophomore Sue's judgment as authoritative. This knowledge does not justify Al's belief formed by deferring to Sue's authority.

Indeed, if $\mathrm{Al}$, while being confused on the matter at hand, is not confused on what epistemic authority consists in, he too will arguably not see Sue as an epistemic authority to whose judgment he ought to defer. Thus, when we believe that a person has authority on whether $p$, we can cite this fact, and the fact that she told me that $p$, to explain how we know that $p$. But if, having formed the belief that $p$ by deferring to sophomore Sue, $\mathrm{Al}$ is asked how he knows that $p$, he cannot answer the challenge by pointing to the inferiority of other belief forming mechanisms available to him. This is just not the right kind of answer to the question: 'How do you know?'

Even if the kind of normative evaluation we are interested in involves a weak notion of epistemic entitlement, one that does not suffice to render true belief knowledge, it is doubtful whether JAB1 provides us with an adequate account. JAB1 appears inadequate even if we take it as an account of reasonable belief, or if we focus only on the reflective thinker's own perspective. Thus, it is unclear whether a subject can hold a belief, knowing that he only holds it because this is what an unreliable thinker believes, and because other available ways of deciding on what to believe are even less reliable. Again, this does not seem to be the right kind of reason when it comes to belief. Moreover, even if he could somehow sustain his belief while knowing that it is not supported by the right kind of reason, because he can know this, his belief will arguably not be a reasonable one, at least not in an epistemic sense.

To some extent, Zagzebski seems to be aware of this problem with JAB1. Thus she notes that JAB1 is 'not sufficient to justify taking a belief on epistemic authority without qualifications ... [for] I might judge that even though the putative authority is more likely to get the truth whether $p$ than I, the authority is not very likely to get the truth either' (Zagzebski 2012: 111). However, she does not explain what other conditions must be met for a belief on authority to be justified or reasonable. But our discussion of what epistemic authority consists in may suggest what 
element, missing from JAB1, must be part of any plausible justification of belief on authority: If to have authority is to have the power to provide others with pre-emptive reasons for belief that allow one's good reasons for believing something to support others' belief in the same thing, then to be justified in believing on authority, one must be justified in believing that the putative authority has good reasons for believing as she does. This is what $\mathrm{Al}$ is not justified in believing about Sue.

Zagzebski also fails to provide a good explanation of why the conditions specified by JAB1 are likely to be fulfilled by believing on authority: Why are we more likely to form a true belief and avoid a false belief if we treat a putative authority's belief as giving us a reason that pre-empts other evidence, rather than by adding it to other evidence available to us? If I do not trust my own judgment, then it may be obvious why I should let someone else's judgment replace my own. But this is not a line of argument available to Zagzebski, whose argument for the rationality of believing on authority is based on the rational inescapability of self-trust. And while the argument from self-trust might establish that sometimes I should trust another person's way of getting a belief more than I trust the way in which I would get a belief, it is not clear why Zagzebski thinks that this justifies believing on the person's authority. Why think that in such a case 'the conscientious thing to do is to let the other person stand in for me in my attempt to get the truth' (2012: 105)? After all, Zagzebski employs a weak notion of trust, such that her claim about the rational inescapability of trusting others only entails that the beliefs of those trusted gives me a prima facie reason to believe as they do (2012: 68). So if I have a reason to trust the putative authority's way of forming beliefs more than I trust my own, does this not require treating it as a weightier prima facie reason, rather than as a reason with pre-emptive force?

Zagzebski (2012: 114) responds to this challenge by drawing on Raz's financial shares argument. Consider a case where I am faced with a practical decision - 'whether or not to sell certain shares' (Raz 1986: 67), and suppose that I am given advice by a financial expert, such that all that I know about her is that she is more likely to make the right decision than I am when I form an independent judgment. Raz argues that in such a case I can do no better than by allowing the expert's judgment to pre-empt my judgment altogether. If instead I treat it as providing me with an additional prima facie reason, I will not do as well. For 'only by allowing the authority's judgment to pre-empt mine altogether will I succeed in improving my performance and bringing it to the level of 
the authority' (1986: 68): Only in this way can I lower my rate of mistake so that it matches that of the expert. If instead I assign some weight to my own independent judgment and some (greater) weight to hers, in a way that will allow her judgment to reverse my own in a certain proportion of the cases, then my rate of mistake would still be higher than the expert's, even if it would be lower than the rate of mistake of my independent judgment: My rate of mistake will likely match the authority's low rate of mistake in that proportion of the cases where my judgment conforms to hers, but will match the higher rate of mistake of my independent judgment in those cases where my judgment differs from hers.

Zagzebski accepts this argument as sound, and takes it as showing that in such cases 'treating [an] authority's belief that $p$ as just one reason among others to believe $p$... will worsen my track record in getting the truth' (2012: 114). For if Raz's argument is sound, she claims, 'it does not matter whether the authority's judgment is about what to do or about what to believe' (Zagzebski 2012: 115). But this is a mistake. While I agree that under certain conditions taking beliefs on authority is both justified and the best epistemic strategy available to us, I don't think that Raz's financial shares argument shows this. For, pace Zagzebski, it does matter whether we are considering a practical question, of the kind considered by Raz, or the question what to believe.

In the kind of practical case described by Raz, there are only two qualitatively different options - 'Sell' and 'Don't Sell' - and two possible states of the world: one in which 'Sell' is best, another in which 'Don't Sell' is best. Given appropriate assumptions, which are arguably satisfied in the case described by Raz, ${ }^{8}$ always following the expert's judgment makes it most likely that you will choose the best option (and most likely that you will avoid the worst), and is therefore the best possible strategy. However, in cases where the question is what to believe, even if there are also just two relevant states of the world $-p$ and not- $p$, there are always (at least) three qualitatively different options: 'believe $p$ ', 'believe

\footnotetext{
${ }^{8}$ For Raz's argument to work, it does not suffice that always conforming our judgment to that of the expert will make us least likely to make a mistake, that is, to choose an option that is not best. To be successful, the argument must also make assumptions about how the payoffs of a mistake will depend on the actual state of the world. It will succeed, e.g., if the payoff of the best option is the same in the case where the best option is 'sell' and where the best option is 'don't sell' (and likewise for the worst option), so that we do not care more about making one type of mistake rather than the other. But this condition is often satisfied, and is arguably often satisfied in the kind of case discussed by Raz.
} 
not- $p$ ', and 'suspend judgment'. In the practical case described by Raz, there is no third option, in the sense that the possible payoffs of notdeciding are identical to that of deciding not to sell. In contrast, in the case of belief the possible epistemic payoffs of withholding judgment are different both from those of 'believing $p$ ' and of 'believing not- $p$ '. Even if the expert's rate of mistake is lower than my own independent rate of mistake, so that always following the expert's judgment makes it most likely that I will choose the best option (believing truth), it does not follow that this is the best possible strategy. For I can significantly improve my chances of avoiding the worst option - falsely believing - if I do not allow the expert's judgment to pre-empt my own. By suspending judgment in at least some proportion of the cases in which she believes $p$ and I independently believe not- $p$ (or vice versa) - cases in which she is much more likely to be mistaken compared to cases on which we agree - I can lower the probability of error not only below that of my own independent judgment, but also below that of the expert. Accordingly, even if all I know is that she is more likely to form the correct judgment than I independently am, when the issue is what to believe, it is simply not the case that I will be more likely to form a true belief and avoid a false belief if I allow the expert's judgment to pre-empt mine. ${ }^{9}$

I conclude therefore that Zagzebski's attempt to justify our believing on authority, by applying the Razian framework to the domain of belief, is inadequate. It fails to set an adequate standard for the justification of belief on authority; and it fails to show that believing on authority ever satisfies those standards that it does set. This does not mean that

${ }^{9}$ Note that this objection to the applicability of Raz's financial-shares argument to the case of belief depends on Zagzebski's specification of our epistemic goals in terms of believing truth and avoiding error. If these are our epistemic goals then we have an option - that of withholding judgment - that, while not best, allows us to guarantee an epistemic payoff which is second-best. It is because of the availability of this option that we should not always adopt the expert's judgment, even if doing so is most likely to result in the optimal payoff. If, however, our epistemic goal is different from that specified by Zagzebski, then it might be possible to apply Raz's financial-shares argument to the case of belief without succumbing to the objection, if this alternative conception does not allow us to guarantee an epistemic payoff which is second-best. This may suggest, in line with other objections to Zagzebski's account made here, that a successful justification of believing on authority would most likely appeal to the epistemic goal of holding doxastic attitudes that fit the evidence. Zagzebski comes close at one point to proposing that believing on authority should be justified in terms of such an evidential goal, but rejects this, claiming that believing on the evidence is neither our ultimate epistemic goal, nor our most important one (2012: 110). 
Zagzebski is mistaken in her important claim, that we are often justified in treating a thinker's belief as a reason that has pre-emptive force and that we are sometimes rationally required to do so. On the contrary, this important claim seems to me to be quite true (Keren 2006; 2014). However, what our discussion suggests is that in order to show that it is true we must be more attuned to the differences between the way authority functions in the practical and epistemic domains.

Our discussion suggests that both an adequate account of what epistemic authority consists in, and an adequate explanation of why believing on authority can be justified, must appeal to the good reasons for the (same) belief that the authoritative thinker has. In accounting for what epistemic authority consists in, we ought not to say that it consists in the ability to generate reasons to believe something pre-emptively in the strong sense; instead, it consists in the power to provide others with pre-emptive reasons for belief that allow their beliefs to be supported by the authority's good reasons for belief. And in presenting an account of the justification of our believing on authority, we will have to appeal to these good reasons, and to the support they can provide to our belief: first, in specifying what conditions must be met for our belief on authority to be justified; and second, in explaining how, by allowing the authority's judgment to pre-empt our own, these conditions can be met. In this, the justification of believing on authority will differ not only in details, but in structure, from the justification of acting on authority. In explaining our justification for doing $\Phi$ on an authoritative command, we need not appeal to reasons for $\Phi$ 'ing existing independently of the command. After all, it is the command itself that can generate these reasons. In contrast, in explaining our justification for believing $p$ on an authoritative testimony, we must appeal to reasons for $p$ which the authority has independently of her telling us that $p$, and to our reasons for believing that such reasons might support our own belief if we believe on authority.

Acknowledgement. Work on this paper was supported by the Israel Science Foundation (grant no. 714/12). For helpful comments on the paper, I am grateful to Ariel Meirav and Saul Smilansky. For their helpful comments, advice and encouragement throughout my work on the concept of epistemic authority, I am especially grateful to Philip Kitcher and Joseph Raz. 


\section{BIBLIOGRAPHY}

Enoch, David. 2014. 'Authority and Reason-Giving', Philosophy and Phenomenological Research, 89 (2): 296-332

Graham, Peter. 2000. 'Conveying Information', Synthese, 123 (3): 365-92

Jones, Ward E. 2002. 'Dissident versus Loyalist: Which scientists should we trust?', The Journal of Value Inquiry, 36 (4): 511-20

Keren, Arnon. 2006. 'Testimony, Science and the Social: Obtaining Knowledge from Authorities', PhD diss., Columbia University

Keren, Arnon. 2007. 'Epistemic Authority, Testimony and the Transmission of Knowledge', Episteme, 4: 368-81

Keren, Arnon. 2014. 'Trust and Belief: A Pre-emptive Reasons Account', Synthese, 191 (12): 2593-615

Raz, Joseph. 1986. The Morality of Freedom (Oxford: Clarendon Press)

Raz, Joseph. 2006. 'The Problem of Authority: Revisiting the Service Conception', Minnesota Law Review, 90: 1003-44

Williamson, Timothy. 2000. Knowledge and its Limits (Oxford: Oxford University Press)

Zagzebski, Linda Trinkaus. 2012. Epistemic Authority: A Theory of Trust, Authority, and Autonomy in Belief (Oxford: Oxford University Press)

Zimmerman, Michael. 1996. The Concept of Moral Obligation (Cambridge: Cambridge University Press) 